\title{
Evaluation of Pakistani goat breeds for genetic resistance to Haemonchus contortus
}

\author{
Masroor Ellahi Babar ${ }^{1}$, Tanveer Hussain ${ }^{1}$, Muhammad Sarfraz Ahmad ${ }^{2}$, Akhtar Ali $^{3}$, \\ Kamran Abbas ${ }^{3}$, Muhammad Muddassir $\mathrm{Ali}^{4}$ \\ ${ }^{1}$ Virtual University of Pakistan, Department of Bioinformatics, Lahore, Pakistan \\ ${ }^{2}$ Provincial Diagnostic Laboratory, Department of Livestock and Dairy Development, Lahore, Pakistan \\ ${ }^{3}$ University of Veterinary and Animal Sciences, Institute of Biochemistry and Biotechnology, Lahore, Pakistan \\ ${ }^{4}$ Afyon Kocatepe University, Department of Molecular Biology and Genetics, \\ Afyonkarahisar, Turkey \\ Received April 7, 2014 \\ Accepted October 22, 2014

\begin{abstract}
This study aimed to evaluate the genetic resistance of Pakistani goat breeds (Beetal, Teddy, Angora, Nachi) against Haemonchus contortus. In total, 13 animals of each breed, irrespective of sex, were selected. Following artificial infection with 5000 L3 (third stage) larvae of Haemonchus contortus to each animal, susceptibility and resistance of each breed was then assessed on the basis of body weight, feacal egg counts, packed cell volume and FAMACHA system on days $0,28,35$, and 42 . Variation in response of all goat breeds to $H$. contortus was observed. Better resistance was observed in Teddy and Beetal breeds $(P<0.05)$ followed by Nachi and Angora breeds. Genetic diversity was noted among these four goat breeds which could be explored further to minimize the use of anthelmintics and to exploit the genetic potential of the different goat breeds.
\end{abstract}

Genetic variability, FAMACHA, Beetal goat, packed cell volume

Developing countries are rich in goat genetic resources. China, India, and Pakistan are top goat meat producing countries in the world. The goat population in Pakistan is 53.8 million, ranking third in the world (Khan et al. 2008). Good quality meat is exported in most of the Middle East and other Asian countries from Pakistan thus contributing an important role in the country's economy. However, parasitic infestation in goats impedes better production and growth of goats. Among the many parasites, Haemonchus contortus is of major concern as it is a voracious blood sucker. This parasite causes anaemia, low packed cell volume (PCV), internal fluid accumulation, and diarrhea dehydration by sucking the blood from abomasum, and may even lead to death in heavy infestation. Consequently, $H$. contortus plays an integral role in reduction of the overall productivity and profitability of an animal (Terrill et al. 2011). Strategies should be designed to cut down this problem. One of the sustainable options is the selection of goat breeds resistant to $H$. contortus. This strategy will provide animals with better resistance against gastrointestinal (GI) parasites and anthelmintic resistance, thus having overall better growth and performance (Baker et al. 2001). Recent studies have focused on the finding of genetic resistance against $H$. contortus at the molecular level in different goat breeds in advanced countries (Alberti 2012; Corley and Jarmon 2012a; Corley and Jarmon 2012b). Some developing countries have started this approach (Chiejina and Behnke 2011). But most developing countries, including Pakistan, are lacking in adopting this approach even at the phenotypic level for finding the native resistant goat breeds. This paper provides substantial evidence on the genetic variation for resistance to GI nematode parasites (especially H. contortus) in four goat breeds of Pakistan. 
Location and climate

\section{Materials and Methods}

The study was conducted at the Angora Goat Farm, Rakh Khairewala, District Layyah (Pakistan's largest small ruminant farm with 14,472 acres of land) under the Directorate of Small Ruminants. The climate is warm temperate with mean maximum and minimum temperatures, daily relative humidity, and mean annual rainfall of $45^{\circ} \mathrm{C}$ and $12{ }^{\circ} \mathrm{C}, 80 \%(\max )$ and $54 \%(\min )$, and $135 \mathrm{~cm}$, respectively.

Animal characteristics and management

Four goat breeds Beetal, Teddy, Angora, Nachi were selected. The locality of all breeds was Punjab districts except for Teddy, which is also found in Azad Jammu and Kashmir (AJK). Beetal and Teddy are used for meat and milk purposes, Angora is raised mainly for hair, while Nachi serves for meat, milk and hair production. All selected breeds were kept under uniform management conditions. Animals were not allowed to go out for open grazing to minimize the chances of getting the internal nematodes infestation from field and all were offered total mixed ration (TMR) at $3 \%$ body weight daily. TMR consisted of corn silage, wheat straw, and mineral mixture. All selected animals were dewormed by administering albendazole at the dose of $10 \mathrm{mg} / \mathrm{kg}$ orally (Albenzole granules; Selmore Agency, Pakistan).

\section{Experimental design and indicators}

In total, 13 animals of each breed at the age between 5 to 8 months were selected. Out of 13 animals of each breed, two animals of each breed were kept as control. Larvae 3 of $H$. contortus were produced and used as challenge to the selected animals with controlled dosage. Ethical permission was taken from the Ethics Committee of the University of Veterinary and Animal Sciences Lahore, Pakistan prior to start the experiment. Haemonchus contortus was obtained from the positive field sample from goats after faecal egg count using a microscope. The eggs were cultured in the laboratory up to stage L3. On day 0 the initial readings were taken and doses of 5000 L3 were administered to the animals. Data were recorded for evaluating the susceptibility and resistance of each breed against $H$. contortus by body weight, feacal egg counts (FEC), and packed cell volume (PCV) by Wintrobe's method (Maxwell and Wintrobe 1929) and FAMACHA on days 0, 28, 35, and 42. Faecal samples were collected directly from rectum and microscopic examination was carried out to count the eggs by using McMaster technique. Blood samples with anti-coagulant (ethylene diamine tetraacetic acid; EDTA) were taken from the jugular vein. Packed cell volume percentage was determined by the microhaematocrit method. FAMACHA system was used to determine the level of anaemia. The eye was examined in the sunlight and the colour was compared with the FAMACHA card as per instructions. The highest value (5) showed highly anaemic animals whereas the lowest value (1) indicated healthier animals.

\section{Statistical analysis}

For differences among breeds in terms of FEC, PCV, and body weight, FAMACHA was performed using the SAS version 6 (SAS Institute Inc., 1996). ANOVA was used to determine the difference among breed data. Differences were considered significant at $P \leq 0.05$.

\section{Results}

The FEC varied $(P<0.05)$ between goats within breeds and between weeks of exposure. A marked difference $(P<0.05)$ was observed in FEC among four breeds and Teddy and

Table 1. Analysis of variance (ANOVA) for faecal egg count among goat breeds.

\begin{tabular}{lcrrrr}
\hline $\begin{array}{l}\text { Source } \\
\text { of variance }\end{array}$ & $\begin{array}{c}\text { Degree of } \\
\text { freedom }\end{array}$ & Sum of square & Mean of square & F ratio & $\operatorname{Pr}>$ F \\
\hline Breed & 3 & 863667.96 & 287889.32 & 3.50 & 0.015 \\
Dose & 1 & 380461.12 & 380461.12 & 4.63 & 0.032 \\
Reading & 4 & 3607612.39 & 901903.10 & 10.98 & $<0.0001$ \\
Sex & 1 & 20882.87 & 20882.87 & 20882.87 & 0.614 \\
Breed $\times$ dose & 3 & 1271858.87 & 423952.96 & 5.16 & 0.001 \\
Breed $\times$ reading & 12 & 22900616.07 & 1908384.67 & 23.22 & $<0.0001$ \\
Breed $\times$ sex & 3 & 51096.87 & 17032.29 & 0.21 & 0.8913 \\
Dose $\times$ reading & 4 & 6577859.26 & 1644464.81 & 20.01 & $<0.0001$ \\
Sex $\times$ dose & 1 & 55232.11 & 55232.11 & 0.67 & 0.4130 \\
Sex $\times$ reading & 4 & 10827.71 & 2706.93 & 0.03 & 0.9979 \\
\hline
\end{tabular}


Beetal showed less FEC compared to Nachi and Angora (Table 1). No anaemia and no blood parasites were found on day zero of the experimental period. The mean values per breed, for PCV during the entire trial period are presented in Table 2. Almost similar pattern was observed for PCV in all goat breeds.

Table 2. Analysis of variance (ANOVA) for packed cell volume among goat breeds.

\begin{tabular}{lcrrrc}
\hline $\begin{array}{l}\text { Source } \\
\text { of variance }\end{array}$ & $\begin{array}{c}\text { Degree of } \\
\text { freedom }\end{array}$ & Sum of square & Mean of square & F ratio & $\operatorname{Pr}>$ F \\
\hline Breed & 3 & 199.487617 & 66.495872 & 2.77 & 0.0418 \\
Dose & 1 & 12.507660 & 12.507660 & 0.52 & 0.4712 \\
Reading & 4 & 392.730038 & 98.182509 & 4.08 & 0.0030 \\
Sex & 1 & 36.850219 & 36.850219 & 1.53 & 0.2165 \\
Breed $\times$ dose & 3 & 58.937751 & 19.645917 & 0.82 & 0.4850 \\
Breed $\times$ reading & 12 & 1544.762093 & 128.730174 & 5.36 & $<0.0001$ \\
Breed $\times$ sex & 3 & 77.267839 & 25.755946 & 1.07 & 0.3612 \\
Dose $\times$ reading & 4 & 2.111842 & 0.527961 & 0.02 & 0.9991 \\
Sex $\times$ dose & 1 & 51.689403 & 51.689403 & 2.15 & 0.143 \\
Sex $\times$ reading & 4 & 244.113902 & 61.028475 & 2.54 & 0.03 \\
\hline
\end{tabular}

Significant results $(P<0.05)$ were found for live weight among goat breeds as shown in Table 3. Maximum weight gain was observed in Teddy followed by Beetal, whereas weight loss was seen in the Angora and Nachi breeds. The FAMACHA score showed the level of anaemia due to $H$. contortus in the four breeds (Table 4). The Teddy breed had a lower mean FAMACHA score (2.12) compared to other breeds. The highest level of anaemia was observed after the experimental infection during the trial concluding the susceptibility of this breed to $H$. contortus.

Table 3. Analysis of variance (ANOVA) for weight gain among goat breeds.

\begin{tabular}{|c|c|c|c|c|c|}
\hline $\begin{array}{l}\text { Source } \\
\text { of variance }\end{array}$ & $\begin{array}{l}\text { Degree of } \\
\text { freedom }\end{array}$ & Sum of square & Mean of square & F ratio & $\operatorname{Pr}>F$ \\
\hline Breed & 3 & 162.0262425 & 54.0087475 & 4.90 & 0.0025 \\
\hline Dose & 1 & 20.0364666 & 20.0364666 & 1.82 & 0.1786 \\
\hline Reading & 3 & 17.3619481 & 5.7873160 & 0.53 & 0.66 \\
\hline Sex & 1 & 98.2615569 & 98.2615569 & 8.92 & 0.003 \\
\hline Breed $\times$ dose & 3 & 103.2580429 & 34.4193476 & 3.12 & 0.02 \\
\hline Breed $\times$ reading & 8 & 124.7832460 & 13.8648051 & 1.26 & 0.25 \\
\hline Breed $\times$ sex & 2 & 557.7483911 & 185.9161304 & 16.88 & $<0.0001$ \\
\hline Dose $\times$ reading & 3 & 15.9689437 & 5.3229812 & 0.48 & 0.6942 \\
\hline Sex $\times$ dose & 1 & 11.8776226 & 11.8776226 & 1.08 & 0.3000 \\
\hline Sex $\times$ reading & 3 & 5.0039101 & 1.6679700 & 0.15 & 0.9287 \\
\hline
\end{tabular}

\section{Discussion}

The mean values of all the recorded readings of FEC, FAMACHA, body weight and PCV showed that there was variation in the responses of all goat breeds to the internal parasite (H. contortus). 
Table 4. Analysis of variance (ANOVA) for FAMACHA among goat breeds.

\begin{tabular}{lccccc}
\hline $\begin{array}{l}\text { Source } \\
\text { of variance }\end{array}$ & $\begin{array}{c}\text { Degree of } \\
\text { freedom }\end{array}$ & Sum of square & Mean of square & F ratio & Pr $>$ F \\
\hline Breed & 3 & 10.86 & 3.621 & 12.79 & $<0.0001$ \\
Dose & 1 & 2.90084390 & 2.90084390 & 10.24 & 0.0015 \\
Reading & 4 & 57.4357 & 14.3589 & 50.71 & $<0.0001$ \\
Sex & 1 & 0.177 & 0.17712007 & 0.63 & 0.4295 \\
Breed $\times$ dose & 3 & 2.9170 & 0.972 & 3.43 & 3.43 \\
Breed $\times$ reading & 12 & 16.01441980 & 1.33453498 & 4.71 & $<0.0001$ \\
Breed $\times$ sex & 3 & 1.51101841 & 0.50367280 & 1.78 & 0.1509 \\
Dose $\times$ reading & 4 & 2.84482532 & 0.71120633 & 2.51 & 0.0416 \\
Sex $\times$ dose & 1 & 0.00962448 & 0.00962448 & 0.03 & 0.8538 \\
Sex $\times$ reading & 4 & 1.82021833 & 0.45505458 & 1.61 & 0.1720 \\
\hline
\end{tabular}

Packed cell volume and FEC are considered valuable for finding whether breeds have resistance against internal nematodes. The PCV is a measure of resilience by showing the animal's ability to endure against infestation, and FEC points out indirectly the resistant animal. Ideally, there should be low FEC and higher PCV in genetically resistant animals. These traits are key to evaluate the genetic resistance among breeds against nematode parasites and they are usually estimated by the statistical estimates of heritability for finding resistance within breeds.

The mean live weight gain in resistant breeds was due to their ability to cope with the internal nematode infection compared to susceptible breeds. Live weight has also its significance in the judgment of resistance and susceptibility status of sheep/goats as was formerly implicated by different authors (Amarante et al. 2004; Burke and Miller 2004; Vanimisetti et al. 2004; Mugambi et al. 2005). All the breeds continued to grow but they could not gain normal weight due to haemonchosis. Breeds showed a significant difference $(P<0.001)$ at all the weighing times, contrary to Vanimisetti et al. (2004). The practicality of the weight gain/loss criterion in the assessment of genetically resistant breeds is supposed to rely on the similarity or dis-similarity in the hereditary potential, performance, and overall size of animals.

Since anaemia is the primary pathologic effect from infection with $H$. contortus, FAMACHA system could be a valuable approach for selecting resistant breeds. However, this tool should be employed along with other tools (Bath et al. 2001). FAMACHA could be helpful in improving the herds or flocks in addition to minimizing the cost and anthelmintic resistance (Bath et al. 2001). The present findings reveal greater significant associations among the FEC, PCV, and the eye score. Previously, there was an established fact that breed resistance against $H$. contortus evaluated on the FEC and PCV indicators are moderately hereditary traits (Kaplan 2005), but the current study has indicated that FAMACHA scores could also be used as a heritable trait in investigating the resistance of goat breeds to the H. contortus infection (Van Wyk and Bath 2002). Thus this qualitative measure coupled with PCV estimation produced significant findings in establishing the fact of immune suppressed and resistant breeds. Moreover, the FAMACHA tool could be used for the culling of susceptible animals to avoid the transmission of a poor genetic pool from herds, exploiting the best genetic pool with greater genetic herd resistance against $H$. contortus. Such achievement could not be attained by using conventional anthelmintic treatment (Kaplan et al. 2004).

The recorded data showed that the Angora goat has more tendencies to infestation from 
this parasite. This breed is not native to our environment and was imported from foreign countries. Out of our local animals Teddy and Beetal goat showed better resistant behaviour and hence are considered as immune competent. On the other hand, Nachi goat showed less tendency to resist against $H$. contortus. After taking all the readings, deworming was done twice using the best effective anthelmintic drug to clear the selected animals from the parasitic load.

In conclusion, genetic heritability to $H$. contortus within breeds should be considered to evaluate the heritabilities of the studied indicators in goats under our native conditions and to find the epidemiology and control of $H$. contortus in goats.

\section{Acknowledgements}

The International Atomic Energy Agency is acknowledged for funding this study under Coordinated Research Program, Identification of Molecular Markers for Internal Nematode Resistance in Sheep and Goat Breeds of Pakistan. We appreciate the Livestock and Dairy Development Department, Punjab for facilitation at farm level and the Department of Parasitology, University of Agriculture, Faisalabad, and the Department of Parasitology, University of Veterinary and Animal Sciences, Lahore for helping in culture of Haemonchus.

\section{References}

Alberti EG, Zanzani SA, Ferrari N, Bruni G, Manfredi MT 2012: Effects of gastrointestinal nematodes on milk productivity in three dairy goat breeds. Small Rumin Res 106S: S12-S17

Amarante AFT, Bricarello PA, Rocha RA, Gennari SM 2004: Resistance of Santa Ines, Suffolk and Ile de France sheep to naturally acquired gastrointestinal nematode infections. Vet Parasitol 120: 91-106

Baker RL, Audho JO, Aduda EO, Thorpe W 2001: Genetic resistance to gastro-intestinal nematode parasites in Galla and Small East African goats in the sub-humid tropics. J Anim Sci 73: 61-70

Bath GF, Hansen JW, Krecek RC, VanWyk A, Vatta AF 2001: Sustainable approaches for managing haemonchosis in sheep and goats. Final report of FAO Technical Cooperation Project No. TCP/SAF8821(A).

Burke JM, Miller JE 2004: Relative resistance to gastrointestinal nematode parasites in Dorper, Katahdin and St. Croix lambs under conditions encountered in the south eastern region of the United States. Small Rumin Res 54: $43-51$

Chiejina SN, Behnke JM 2011: The unique resistance and resilience of the Nigerian West African Dwarf goat to gastrointestinal nematode infections. Parasites Vectors 4:12

Corley M, Jarmon A 2012a: Interleukin 13 as a biomarker for parasite resistance in goats naturally exposed to Haemonchus contortus. J Agri Sc 4: 31-40

Corley M, Jarmon A 2012b: A common Beta Tubulin Isotype-1 Gene Single Nucleotide Polymorphism as a tool for detection and quantitation of anthelmintic resistant Haemonchus contortus in Grazing Goats. J Agri Sci 4: $1-11$

Kaplan RM 2005: Responding to the emergence of multiple-drug resistant Haemonchus contortus: Smart Drenching and FAMACHA ${ }^{\circ}$. In: Proceedings of the Kentucky Veterinary Medical Association 2005, Morehead Clinic Days Conference, Morehead, Kentucky, June 4-5

Kaplan R M, Burke JM, Terrill TH, Miller JE, Getz WR, Mobini S, Valencia E, Williams MJ, Williamson LH, Larsen M, Vatta AF, 2004: Validation of the FAMACHA ${ }^{\circ}$ eye color chart for detecting clinical anemia in sheep and goats on farms in the southern United States. Vet Parasitol 123: 105-120

Khan MS, Khan MA, Mahmood S 2008: Genetic resources and diversity in Pakistani goats. Int J Agri Bio 10: 227-231

Maxwell M, Wintrobe MD 1929: The volume and hemoglobin content of the red blood corpuscles. Amer J Med Sci 177: 513-523

Mugambi JM, Audho JO, Baker RL 2005: Evaluation of the phenotypic performance of a Red Maasai and Dorper double backcross resource population: natural pasture challenge with gastrointestinal nematode parasites. Small Rumin Res 56: 239-251

Terrill TH, Miller JE, Burke JM, Mosjidis JA, Kaplan RM 2011: Experiences with integrated concepts for the control of Haemonchus contortus in sheep and goats in the United States. Vet Parasitol 11: 043

Van Wyk JA, Bath GF 2002: The FAMACHA ${ }^{\circ}$ system for managing haemonchosis in sheep and goats by clinically identifying individual animals for treatment. Vet Res 33: 09-529

Vanimisetti HB, Greiner SP, Zajac AM, Notter DR 2004: Performance of hair sheep composite breeds: Resistance of lambs to Haemonchus contortus. J Anim Sci 82: 595-604 